\title{
Effects of sound environment on the sleep of college students in China
}

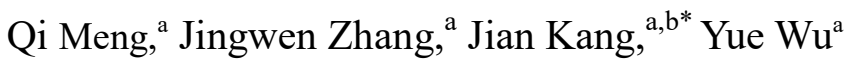

${ }^{a}$ Key Laboratory of Cold Region Urban and Rural Human Settlement Environment Science and Technology, Ministry of Industry and Information Technology, School of Architecture, Harbin Institute of Technology, Harbin 150001, 66 West Dazhi Street, Nan Gang District, Harbin, China ${ }^{\mathrm{b}} \mathrm{UCL}$ Institute for Environmental Design and Engineering, University College London (UCL), London WC1H 0NN, UK

*Corresponding Author

Prof. Jian Kang, j.kang@,ucl.ac.uk

Dr. Yue Wu, wuyuehit@hit.edu.cn

\begin{abstract}
Chinese college students reside primarily in four-person bedrooms and even six-person bedrooms, where the sound from roommates may affect their sleep. Therefore, the purpose of the present study is to investigate the effects of different sound sources and sound levels on sleep for college students in China. Based on sleep quality measurements, acoustic environment measurements, and a questionnaire survey with 90 participants in a typical residence hall in Harbin city, China, the results are as following: First, $68.89 \%$ of college students experienced sleep deprivation, and indoor noise was the most influential environmental factor among 15 disruptors that disturbed $50 \%$ of college students. Second, the number of occupants per room was a significant factor affecting the background sound level of sleep, which was highest when the number of occupants was two, and lowest when the number was five. Third, deep sleep time and rapid eye movements (REM) sleep time decreased 1.7 minutes and 1.4 minutes per 1dBA (decibel with A-weight), with $\mathrm{R}^{2}=.352$ and .332 , respectively $(\mathrm{p}<.001)$. In terms of the effect of sound sources on sleep, sleep was mostly disturbed by roommate conversation $(77.42 \%)$, and noise caused by roommate sleep-related activities was the most common source of activities (67.74\%). The present study can provide guidelines to help enhance the sleep quality of Chinese college students through improvements in the sound environment.
\end{abstract}

Keywords: college students, sound environment, sound source, sleep quality, Pittsburgh Sleep Quality Index (PSQI)

2019 Science of the Total Environment

Date received: 12 November 2019 Date accepted: 26 November 2019

Publish online: 28 November 2019 


\section{Introduction}

A report from China's Ministry of Education noted that about 31.43 million students live in residence halls, accounting for $82 \%$ college students in China, and $80 \%$ of dorms are four-person or even six-person bedrooms (Ministry of Education of the People's Republic of China, 2019). Sleep plays an essential role in college students' daily life (Gawlik et al., 2019; George, 2007; Gregory et al., 2004; Orzel-Gryglewska, 2010; Pilcher and Huffcutt, 1996; Zaharna and Guilleminault, 2010). Such a complex and unique environment inevitably brings about an impact on sleep for college students. First, sleep is the only other biological necessity of our bodies in addition to air, water, and food (Gregory et al., 2004). Sleep loss has been implicated in a variety of adverse health outcomes (Zaharna and Guilleminault, 2010), including cardiovascular abnormalities (Gawlik et al., 2019), immunological problems (Orzeł-Gryglewska, 2010), psychological health concerns (Pilcher and Huffcutt, 1996), and neuro-behavioural impairment that can lead to accidents (George, 2007). Furthermore, college years are when students gain critical knowledge, skills, human capital, and credentials to become successfully employed and contribute to society after graduation (Astin et al., 2019). Previous studies have confirmed that sleep-deprived students tend to learn material less efficiently, which could lead to a lower grade point average (GPA; Gilbert and Weaver, 2010). When sleep deprivation occurs during college years, it presents an obstacle to maximising individuals' success during this critical time.

There have been studies that have focused on sleep among college students (Hershner and Chervin, 2014; Lund et al., 2010; Van Dongen et al., 2003). However, some studies have reported high rates of insufficient sleep among college students (Gilbert and Weaver, 2010; Lund et al., 2010). Therefore, a better understanding of the causes of sleep deficits in the college student population is needed. Sleep deprivation occurs for multiple reasons, some of which are physiological and others behavioural. Many students have inadequate sleep hygiene that, in conjunction with their delayed circadian rhythm, contributes to sleep deprivation (Hershner and Chervin, 2014). The mechanisms of some influential factors have been studied. In terms of substance use, alcohol use has been shown to lead to shortened sleep latency and the promotion of fragmented sleep in the latter half of the night (Amlander and Fuller, 2005). Caffeine, taken at night, has been found to increase sleep latency, reduce sleepiness, and improve the ability to sustain wakefulness (Walsh et al., 1990). Further, stimulants have been demonstrated to increase sleep latency, suppress REM sleep, and worsen sleep quality (Amlander and Fuller, 2005; Clegg-Kraynok et al., 2011). Frequent cell phone use at bedtime has been associated with difficulties falling asleep, repeated awakenings, or waking up too early (Thomée et al., 2007). Additionally, researches have indicated that noise is a significant sleep disturbance in college residential sleep environments (Lund et al., 2010; Sexton-Radek and Hartley, 2013). Such studies on the factors influencing sleep have rarely considered how nocturnal environmental noise might affect sleep among college students living in residence halls. However, the sound environments of school gymnasia (Maffei et al., 2009), offices (Kang et al., 2017) and classrooms (Ricciardi and Buratti, 2018) have been studied; therefore, more in-depth research on factors in residence halls that affect college students' sleep is needed.

Sleep has been shown to be disturbed by sound environment (Basner et al., 2010, 2011), and when this disturbance is severe and frequent, it can lead to significant sleep fragmentation and sleep deprivation, which is detrimental to physical and mental health (Basner et al., 2010). Nocturnal environmental noise is considered a major cause of exogenous sleep disturbance, after somatic problems and day tensions (Basner et al., 2011). Most previous studies focused on a certain kind of noise or a specific group of people and have shown that residents exposed to nocturnal environmental noise such as aircraft (Kwak et al., 2016), road (Pirrera et al., 2014), train (Smith et al., 2016), or wind turbine noises (Bakker et al., 2012) or the combination of noises (Lee et al., 2010) at night exceeding a certain sound level can result in sleep disturbances. The effects of noise on sleep among different populations, including infants (Strauch et al., 1993), children (Weyde et al., 2017), adults (Evandt et al., 2017), and other special populations, such as hospitalised patients (Park et al., 2014) and some categories of workers (Azadboni et al., 2018) 
have been studied.

However, relatively less research has examined how nocturnal environmental noise affects college students' sleep in communal living environments that are primarily occupied by four to six persons. When sharing a small room, occupants are exposed to noises from various activities. Research that explores the effects of sound environment on sleep among college students in China may help identify ways to improve their sleep quality. Therefore, using a typical university residence hall in Harbin, China as a case site, and using subjective and objective measures, the present study examined four research questions. First, we addressed the question regarding sound environment being one of the main factors contributing to disturbed sleep in college students, and if it was, what is the proportion and extent of the students' sleep disturbance? Second, we asked, how does the number of occupants affect the nocturnal sound environment of residence halls? Third, we explored how sound levels affect the sleep quality of college students. Fourth, we examined how sound sources affect the sleep quality of college students.

\section{Materials and Methods}

\subsection{Case Site}

Most Chinese university dorms are multi-storey buildings with five to seven floors. Generally, they are planned on a campus, away from outdoor noise resulting from road traffic and industry, and separate units are created for men and women. In China, about $65 \%$ of college dormitories are four-person rooms, 16\% are six-person rooms, and the remaining 19\% are single rooms, double rooms and eight-person rooms. The living area of these units is commonly between 16 and 18 square metres. In addition, undergraduate and graduate students are the primary groups in Chinese colleges, accounting for $98.8 \%$ of the nation's college students (Ministry of Education of the People's Republic of China, 2019).

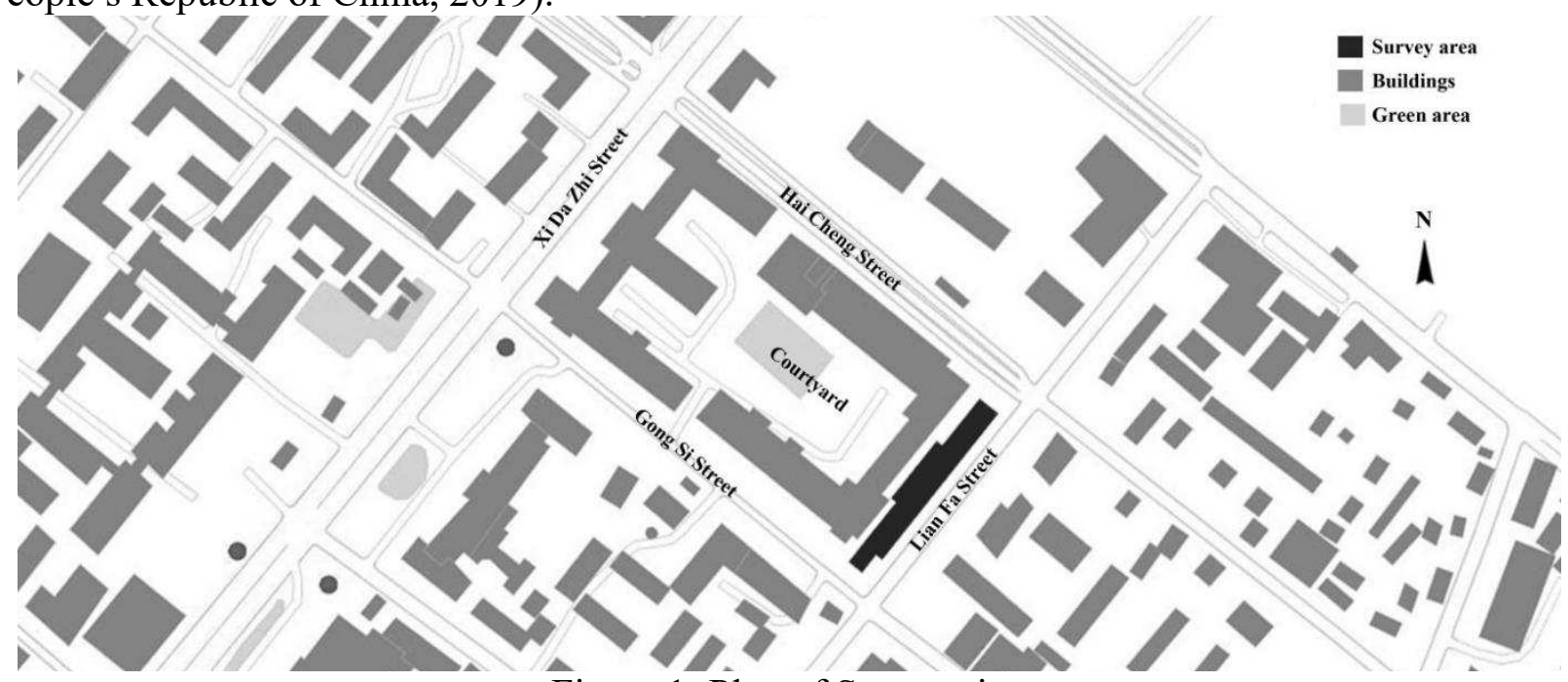

Figure 1: Plan of Survey site.

Field surveys are essential to evaluate the practical environmental settings for sleep (Stansfeld et al., 2000). Since noise is a common environmental hazard, it is a simpler approach to explore the effects of noise in everyday life rather than in laboratory experiments. Thus, field studies are more accurate in reflecting participants' actual sleep patterns (Öhrström and Skanberg, 2004). Study locations were drawn from areas at Harbin Institute of Technology in north-eastern China. It has about 46000 students recruited from all over the country, which make the research results representative of the situation of college students nationwide (Harbin Institute of Technology, 2019). A typical residence hall was chosen for this field survey considering that the focus of the study was the impact of different buildings and their surroundings. The dormitory accommodates 1,262 students, including both undergraduate and graduate students, with similar numbers of men and women. Only four-person and six-person bedrooms are present with an area of 17.5 square metres, and the number of occupants varies from one to six. The building is seven floors high and adjacent to three streets, with one side facing the courtyard. As shown in Figure 1, the other sides 
face Lian Fa Street, Hai Cheng Street and Gong Si Street, all pedestrian streets with a small amount of traffic. Therefore, there are various typical sound sources inside the dormitory building, including snoring, conversation, whispering, footsteps, and keyboard/mouse click with a little outdoor noise.

Male students were living on the first to third floors, and female students were living on the fifth to seventh floors. The fourth floor is divided into two separate parts for women and men. As shown in Figure 2, bedrooms of equal size are on both sides of the corridor. The bedroom is 5 metres long and 3.5 metres wide, and there are two dwelling modes. Students of different grades are distributed on every floor. The undergraduate students primarily reside in six-person bedrooms, which includes upper and lower bunks as shown in Figure 3(a), while the rooms for graduate students are primarily four-person bedrooms, and loft bed with a desk is the main mode as shown in Figure 3(b). Sometimes the number of people living in the bedroom was fewer than the standard number, due to arrangement by the university or personal reasons. Therefore, the number of occupants in the rooms varied from one to six.

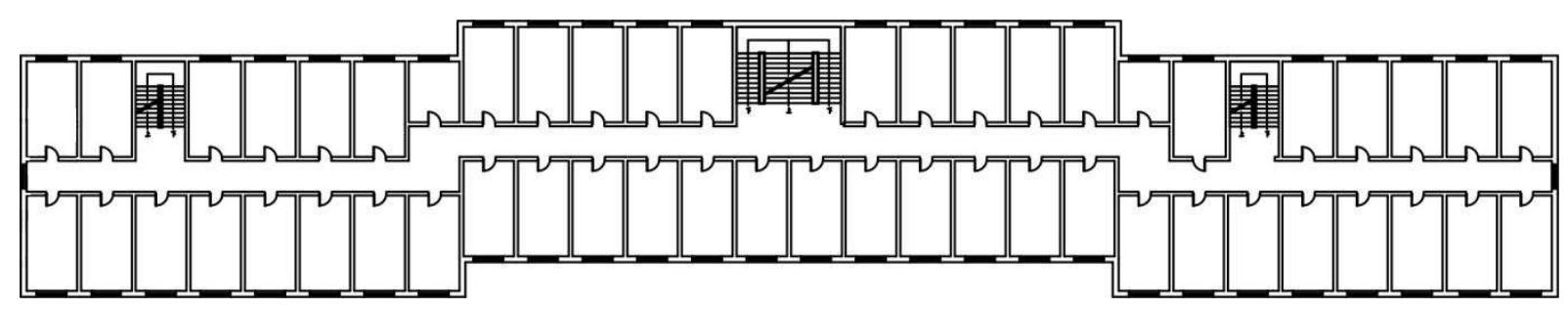

Figure 2: Floor plan of the residence hall.
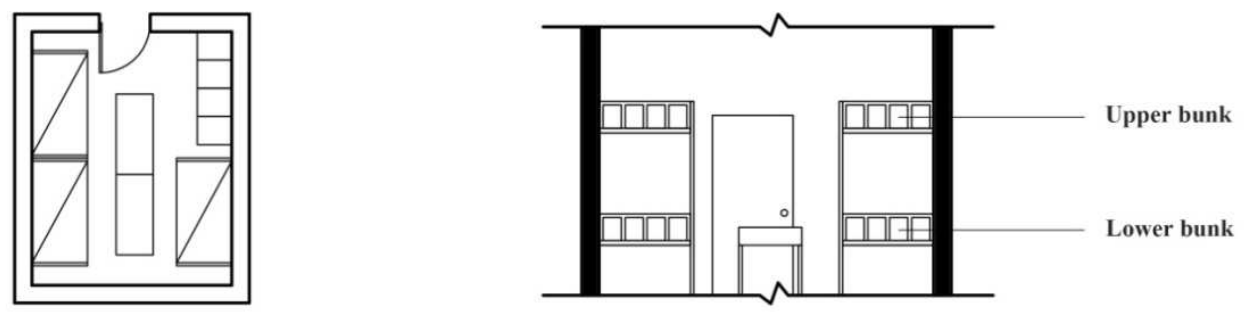

(a)
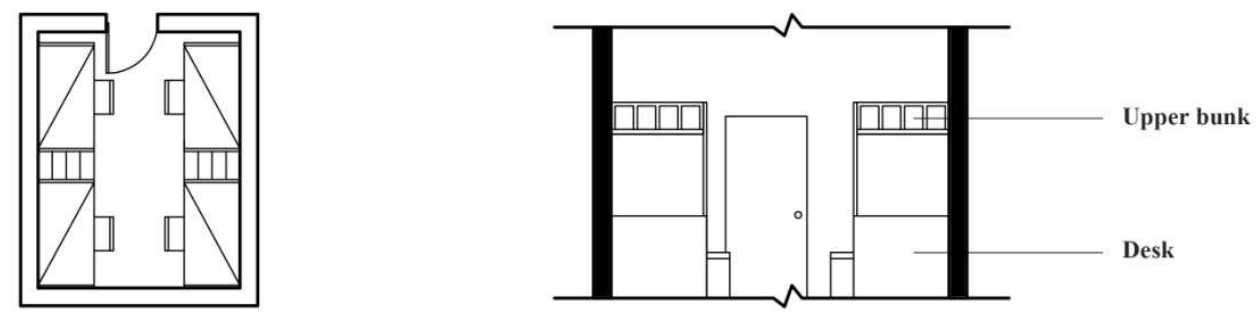

(b)

Figure 3: The plan and the section plan of bedroom: (a) the plan and the section plan of six-person bedroom. (b) the plan and the section plan of four-person bedroom.

\subsection{Participants}

Prior studies have indicated that $80-100$ participants are enough for a questionnaire study on indoor noise and sleep (Ising et al., 2002; Lercher et al., 2010; Thomas et al., 2012). Therefore, considering the variety of gender and grade of students, the number of occupants, as well as different floors, 105 students in the residence hall were chosen for the present study with stratified sampling. They were informed of the purpose, procedures and requirements of the study through 
an e-mail and asked to provide informed consent by e-mail reply. Of them, 93 were willing to participate in the survey, including three participants who did not live in the residence hall during the survey. Ninety valid responses were received. Such sample collection not only makes the sample representative, but also details of individual noise levels inside were easily collected. The participants were aged between 18 and 26, all of whom needed to follow the same routine used during the survey period, without any interference from other events, such as exams or parties. Of the sample $50 \%(\mathrm{n}=45)$ were men, and $50 \%(\mathrm{n}=45)$ were women. Of these, $15.6 \%$ were freshmen $(n=14), 15.6 \%$ were sophomores $(n=14), 17.8 \%$ were juniors $(n=16), 17.8 \%$ were seniors $(\mathrm{n}=16), 17.8 \%$ were first-year graduates $(\mathrm{n}=16)$, and $15.6 \%$ were second-year graduates $(n=14)$. The mean age of the sample was 21 years $(S D=1.9)$. This study was reviewed and approved by the university's institutional review board. Written informed consent was obtained from all participants. As incentives for participation, participants received either a monetary reward or various learning materials reward.

\subsection{Subjective Measurements}

Participants were required to complete a questionnaire once to collect long-term evaluations that included the Pittsburgh Sleep Quality Index (PSQI), other personal characteristics, residence information, and subjective assessment of the nocturnal sound environment.

\subsubsection{Demographic survey}

Participants completed a brief demographic survey. This survey included questions about age, gender, grade level, height, weight, and the number of occupants per room. The position of the bed, including upper bunk beside the window, upper bunk beside the door, lower bunk beside the window, and lower bunk beside the door, were also recorded.

\subsubsection{Self-reported sleep quality}

The PSQI is a measure of the subjective experience of sleep that is a well-established psychometric assessment (Carpenter and Andrykowski, 1998) and is one of the most common subjective methodologies used in sleep research. It can provide an assessment of sleep quality over the previous 30 days. The PSQI differentiates between poor- and good-quality sleepers by measuring seven areas: subjective sleep quality, sleep latency, sleep duration, habitual sleep efficiency, sleep disturbances, use of sleep medication, and daytime dysfunction over the past month (Buysse et al., 1989). The components of the PSQI are scored on a scale from 0 (better) to 3 (worse); therefore, the global PSQI is a score ranging from 0-21. A global score $>5$ indicates a poor-quality sleeper, whereas a score of 5 is indicative of a good-quality sleeper (Spira et al., 2012). For this study, global PSQI scores were split into three categories: optimal $(\leq 5)$, borderline $(6-7)$, and poor $(\geq 8)$ sleep quality for the purpose of achieving relatively even group sizes (Lund et al., 2010). The internal consistency of the PSQI in this study, estimated by Cronbach's alpha, was .76. According to the analysis of the responses to the question 'During the past month, how often have you had trouble sleeping because you ___ in the questionnaire, we received information on the degree of influence of different factors on residents' sleep. The original PSQI only contains options 'A-I' and 'others'. After the statistical analyses, we summarised other factors into 'J-N' as shown in Table 1.

\subsubsection{Evaluation of sound environment of sleeping}

Participants also needed to finish the designed subjective assessment of sleep sound-environment questionnaire for the previous 30 days after interviews, in which participants were required to list perceived sources of sound in the bedrooms. Sound perception and noise sources for disturbance of sleep were evaluated using an 11-point scale (Pirrera et al., 2014), which was scored from 0 to 10 in three stages - before sleep, during sleep, and after waking up. Four sources of noise were evaluated: outdoor noise (e.g. road traffic, construction/industry, wind/rain/storm/lightning, and construction equipment), noise from roommates (e.g. roommates' snores, roommates' conversation, and roommates' whispering), other indoor noises (e.g. footsteps in the corridor and conversation in the corridor), and activities (e.g. activities in the next room, roommates' sleep-related activity, roommates' study and entertainment activities). In the evaluation of the scale of perception, 0 means completely inaudible, and 1-10 indicate just heard 
to very significant. While assessing the impact, 0 means no influence, and 1-10 indicate slight influence to severe influence.

\subsection{Objective Measurements}

\subsubsection{Sound-level measurements}

Nocturnal environmental noise was recorded inside each bedroom simultaneously for seven consecutive days from Monday to Sunday. A total of 45 rooms were measured for ambient noise using sound-level metres separately, which were placed at ear level of participants in bedrooms to record equivalent sound level $\left(\mathrm{LA}_{\mathrm{eq}}\right)$, peak sound levels $\left(\mathrm{L}_{10}, 10^{\text {th }}\right.$ percentiles in $\left.\mathrm{dBA} \mathrm{LA}_{\mathrm{eq}}\right)$, background sound levels $\left(\mathrm{L}_{90}, 90^{\text {th }}\right.$ percentiles in $\left.\mathrm{dBA}^{\mathrm{LA}} \mathrm{A}_{\mathrm{eq}}\right)$ at the measuring point, with slow-style and A-weight (Park et al., 2014) since they are all related to sleep. To better describe the acoustic environment of our study population, we maintained the habitual sleep schedules for the participants as the targeted sleep period studied (Eberhardt et al., 1987). The measurement was carried out in winter, November 2018, for a week. First, the mean noise level value per 10-second epoch was recorded for 24 hours, for seven consecutive days, and then the sound level of individual sleep environment during sleep latency, sleep, and 15 minutes after waking up was calculated according to the measurement of sleep time. Additionally, many previous studies indicate that excessively high or low ambient temperature (Ta) may affect sleep because thermoregulation is strongly linked to the mechanism regulating sleep (Gilbert et al., 2004). In order to avoid the influence of indoor thermal environment on the experimental results, the indoor temperature was measured at the same time. Results from measurements showed that ambient temperatures of the 45 rooms ranged from $22^{\circ} \mathrm{C}$ to $23^{\circ} \mathrm{C}$ due to the central heating system in the residence hall. Prior research has indicated that a comfortable temperature in winter was close to this range (Lan et al., 2014).

\subsubsection{Sleep quality measurements}

The study was designed to objectively measure sleep in relation to noise exposure using actigraphy, which has emerged as a widely accepted tool to tracking sleep and wake behaviour (Ancoli-Israel et al., 2003; Sadeh, 2011). This method provided a more comprehensive evaluation of the potential effect that noise may have on sleep for college students. when considered together with the self-report. An actigraphy device worn on the wrist was given to all participants to record the sleep quality for a minimum of seven consecutive days. Respondents were asked to wear the device on their wrist during all hours of the day and night for the seven days following their survey (Michaud et al., 2016). The sleep monitoring technology adopted by the wristband is based on an electrocardiogram-based technique named cardiopulmonary coupling technology (CPC; Thomas et al., 2005), which can take exact measurements of sleep patterns, including timing and duration of sleep as well as awakenings (Sadeh, 2011). CPC has been proposed recently as an indicator of sleep stability and as an alternative way of characterising sleep (Thomas et al., 2005), and has been used in some sleep-related studies (Chen et al., 2018; Cysarz et al., 2018; Schramm et al., 2013). Although it cannot replace traditional polysomnography due to imperfect sensitivity and specificity to detect wake periods, this tool can provide reasonable estimates for assessing subjects objectively with minimal participant burden for more prolonged periods of time than conventional assessment tools (Martin and Hakim, 2011).

The actigraphy provided key information on sleep patterns, including total sleep time, deep sleep time, light sleep time, REM sleep time, and the number of awakenings bouts which we used for further analysis. In addition, to help interpret the measured data, respondents were asked to complete a basic sleep log about when they went to bed each night. Then, we got the participants' sleep latency each night also using the wrist data, from which we got sound levels of each participant before they fell asleep, during sleep, and after waking up. After the 7-day collection period, respondents were asked to return the completed sleep log along with the sleep watch.

\subsection{Data Analysis}

Based on the collections of sleep data and questionnaires, the software program SvanPC++ (version 3.3.16) was used to analyse the noise data, and the software SPSS (Feeney, 2012) was used to perform the analyses of the data from the survey. Spearman and Pearson correlation tests 
were used to calculate the relationship between sound level and influencing factors, the relationship between data of sleep quality and influencing factors, and the relationship between disturbance of noise sources and sleep duration. A t-test at $p<.01$ and $p<.05$ was used to test for significant differences. Further, linear and nonlinear regression analyses were performed to examine the relationship between noise and sleep duration and between the number of occupants and background sound level among college students. Additionally, an analysis of variance (ANOVA) was used to test for significant differences in self-rated sleep quality between related factors. T-Tests were used to test for gender differences, and paired t-tests were used to determine differences between in-week and weekend behaviours.

\section{Results}

\subsection{Sleep disturbance from sound environment}

Overall, college students reported chronically restricted sleep. Mean total sleep time (time spent actually sleeping, as opposed to being awake in bed) was 6.8 hours $(\mathrm{SD}=1.0)$, bedtime was 00:37 ( $\mathrm{SD}=45$ minutes), rise time was 08:15 ( $\mathrm{SD}=55$ minutes), and sleep latency was 40.5 minutes $(\mathrm{SD}=36.7)$. Table 1 shows responses to individual questions on the PSQI. For the 90 participants who completed the PSQI in its entirety, the average score was 6.27 , with a 95\% confidence interval $(5.64,6.89)$. Of the participants who had poor sleep quality, $68.89 \%$ scored greater than 5 , and $28.89 \%$ scored greater than 8 , which means that $68.89 \%$ of the college students were poor-quality sleepers. Specifically, $71.11 \%$ of students reported lacking the enthusiasm to get things done at least once a week, and $62.22 \%$ reported an inability to fall asleep within 30 minutes at least once a week. High rates of insufficient sleep among college students were also found in other related studies (Gilbert and Weaver, 2010; Lund et al., 2010).

Table 1 shows that $\mathrm{J}$ 'Stress/anxiety' was the most influential factor, which affected more than $60 \%$ of participants' sleep. 'Indoor noise' was the third biggest factor after 'Coffee, Alcohol, staying up late', because of which more than $50 \%$ of participants had trouble sleeping. Excessive noise was also a common reason for sleep disturbance in other studies about college students' sleep measured by PSQI. For example, excessive noise was found to be one of the most common 'other reasons' at a large private university in the American Midwest (Lund et al., 2010).

Table1: Sleep quality measured by the PSQI

\begin{tabular}{lcccc}
\multicolumn{1}{c}{ Pittsburgh Sleep Quality Index } & Bedtime & Sleep latency & Rise time & Total sleep time \\
\hline \multicolumn{1}{c}{ Mean } & $12: 37 \mathrm{am}$. & $40.5 \mathrm{~min}$. & $8: 15 \mathrm{am}$. & 6.8 hours. \\
& $45 \mathrm{~min}$ & $36.7 \mathrm{~min}$ & $55 \mathrm{~min}$ & 1 hour \\
\hline how often have you had trouble & Not during the & Less than once a & Once or twice a & 3 or more times a \\
sleeping because & past week & week & week & week \\
A. Cannot fall asleep within 30 & $37.78 \%$ & $42.22 \%$ & $13.33 \%$ & $6.67 \%$ \\
min & & & & \\
B. Easy to wake up or wake up & $80 \%$ & $13.33 \%$ & $4.44 \%$ & $2.22 \%$ \\
early at night. & & & & \\
C. Go to the toilet at night & $90 \%$ & $6.67 \%$ & $2.22 \%$ & $1.11 \%$ \\
D. Poor breathing & $87.78 \%$ & $10 \%$ & $2.22 \%$ & $0 \%$ \\
E. Cough or snoring & $62.22 \%$ & $26.67 \%$ & $6.67 \%$ & $4.44 \%$ \\
F. Feeling cold & $65.56 \%$ & $21.11 \%$ & $13.33 \%$ & $0 \%$ \\
G. Feeling hot & $60 \%$ & $20 \%$ & $20 \%$ & $0 \%$ \\
H. Nightmare & $68.89 \%$ & $24.44 \%$ & $4.44 \%$ & $2.22 \%$ \\
I. Pain/discomfort & $90 \%$ & $5.56 \%$ & $4.44 \%$ & $0 \%$ \\
J. Stress/anxiety & $28.89 \%$ & $40 \%$ & $26.67 \%$ & $4.44 \%$ \\
K. Coffee, Alcohol, Staying up late & $35.56 \%$ & $13.33 \%$ & $28.89 \%$ & $22.22 \%$ \\
\hline
\end{tabular}


Qi Meng, Jingwen Zhang, Jian Kang, \& Yue Wu. Science of the Total Environment

\begin{tabular}{lcccc} 
L. Outdoor noise & $73.33 \%$ & $17.78 \%$ & $6.67 \%$ & $2.22 \%$ \\
M. Indoor noise & $48.89 \%$ & $26.67 \%$ & $11.11 \%$ & $13.33 \%$ \\
N. Light & $82.21 \%$ & $8.89 \%$ & $6.67 \%$ & $2.22 \%$ \\
Other reasons & $90 \%$ & $6.67 \%$ & $1.11 \%$ & $2.22 \%$ \\
how often have you _ & - & - & - & - \\
Taken medicine to help you sleep? & $100 \%$ & $0 \%$ & $0 \%$ & $0 \%$ \\
$\begin{array}{l}\text { Had trouble staying awake during } \\
\text { social activities? }\end{array}$ & $17.78 \%$ & $28.89 \%$ & $31.11 \%$ & $22.22 \%$ \\
Had a problem getting the & $28.89 \%$ & $35.56 \%$ & $26.67 \%$ & $9 \%$ \\
enthusiasm to get things done? & Very good & Fairly good & Fairly bad & Very bad \\
\hline rate overall sleep. & $8.89 \%$ & $62.22 \%$ & $28.89 \%$ & $0 \%$ \\
\hline Global PSQI & Optimal (1-5) & Borderline (6-7) & Poor $(\geq 8)$ & - \\
& $31.11 \%$ & $40 \%$ & $28.89 \%$ & - \\
\hline
\end{tabular}

In addition, the ANOVA test showed that some personal characteristics had an impact on self-rated sleep quality. Figure 4 shows the result of the question 'rate overall sleep', which indicated that self-rated sleep quality is not equal in different position groups and number groups, and higher scores mean poorer sleep, with significance level $p<0.05$. Participants whose beds were lower bunk or near the door scored higher, which means they sleep worse. This is because there is more corridor noise near the door and more noise from roommate activities on the lower bunk. Besides, groups with greater number of occupants per room rated their sleep quality higher, thinking they have worse sleep. It is noticeable that none of the participants had taken medicine to help sleep in the students sampled, which differs from other studies (Lund et al., 2010).

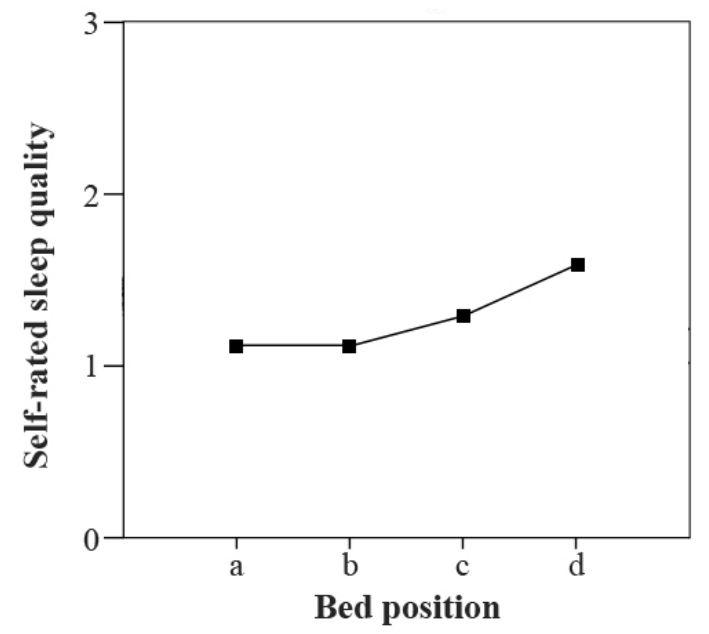

(a) 


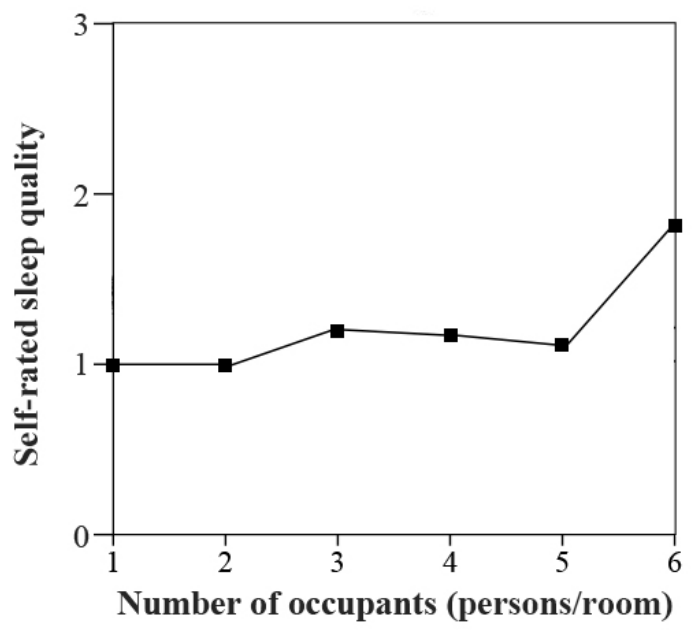

(b)

Figure 4: Comparison of self-rated sleep quality scores among different groups: (a) Comparison of self-rated sleep quality scores among different bed position groups. (b) Comparison of self-rated sleep quality scores among different number groups. (a. upper bunk beside the window. b. lower bunk beside the window. c. upper bunk beside the door. d. lower bunk beside the door.)

\subsection{Effect of number of occupants on nocturnal sound environment}

Result of measurement showed that $\mathrm{LA}_{\mathrm{eq}}$ at night ranged from $21 \mathrm{dBA}$ to $56 \mathrm{dBA}$ in the sample, of which $\mathrm{LA}_{\mathrm{eq}}$ before sleep ranged from $22 \mathrm{dBA}$ to $56 \mathrm{dBA}$. $\mathrm{LA}_{\mathrm{eq}}$ during sleep ranged from $21 \mathrm{dBA}$ to $42 \mathrm{dBA}$, and $\mathrm{LA}_{\mathrm{eq}}$ after waking up ranged from $21 \mathrm{dBA}$ to $50 \mathrm{dBA}$. Average night-time sound levels during sleep were lowest in the three stages, varying within a small range and highest in the stage before sleep with a large variation range. The peak sound level before sleep reaches a maximum of $65 \mathrm{dBA}$ and an average of $41 \mathrm{dBA}$.

As shown in Table 2, the number of occupants per room was a significant factor affecting sound level. Pearson correlation confirms a significant relationship between the number of occupants and $\mathrm{L}_{90}$, with significance level $\mathrm{p}<0.05$. There was also a correlation between the number of occupants and $\mathrm{L}_{10}$, the number of occupants and $\mathrm{LA}_{\mathrm{eq}}$, with significance level $\mathrm{p}<0.01$. In addition, there was a moderate correlation between floor and sound level, especially during sleep, the higher the floor, the significantly lower the sound level. Sound levels also differed significantly by gender in $\mathrm{L}_{10}(32.3 \pm 1.7 \mathrm{dBA}, 30.6 \pm 2.2 \mathrm{dBA})$ during sleep, $\mathrm{L}_{10}(36.9 \pm 4.8 \mathrm{dBA}$, $33.1 \pm 4.2 \mathrm{dBA})$ and $\mathrm{L}_{\mathrm{eq}}(33.9 \pm 4.2 \mathrm{dBA}, 31.2 \pm 4.2 \mathrm{dBA})$ after waking up between men and women with significance level $\mathrm{p}<0.05$. The average sound level of the men's bedrooms was higher than that of the women's bedrooms.

Table2: The relationship between gender, number of occupants, floor and the sound level in each stage.

\begin{tabular}{cccccccccc}
\hline & \multicolumn{3}{c}{ Before sleep (dB SPL) } & \multicolumn{3}{c}{ During sleep (dB SPL) } & \multicolumn{3}{c}{ After waking up (dB SPL) } \\
& $\mathrm{L}_{10}$ & $\mathrm{~L}_{90}$ & $\mathrm{~L}_{\mathrm{eq}}$ & $\mathrm{L}_{10}$ & $\mathrm{~L}_{90}$ & $\mathrm{~L}_{\mathrm{eq}}$ & $\mathrm{L}_{10}$ & $\mathrm{~L}_{90}$ & $\mathrm{~L}_{\mathrm{eq}}$ \\
\hline Gender & - & - & - & $*$ & - & $*$ & $*$ & - & $*$ \\
\hline Number of & $-0.169^{*}$ & $-0.167^{* *}$ & $-0.174^{*}$ & 0.121 & $-0.253^{* *}$ & 0.008 & $0.203^{* *}$ & $-0.441^{* *}$ & 0.100 \\
occupants & & & & & & & & & \\
\hline Floor & -0.051 & $-0.166^{*}$ & -0.007 & $-0.383^{* *}$ & $-0.201^{* *}$ & $-0.312^{* *}$ & $-0.157^{*}$ & -0.033 & $-0.162^{*}$ \\
\hline * $<0.01 ; * \mathrm{p}<0.05$. & & & & & & & \\
\hline
\end{tabular}


Figure 5 shows the relationship between the number of occupants per room and background night-time sound levels measured with A-weight, along with the corresponding regression curves, the coefficient of determination $\mathrm{R}^{2}$, with significance level $\mathrm{p}<0.001$. Different regression curves, including linear ( $\mathrm{R}^{2}$ from .025 to .154$)$, quadratic $\left(\mathrm{R}^{2}\right.$ from .029 to .168$)$ and cubic $\left(\mathrm{R}^{2}\right.$ from .212 to .510), were used to determine the best fit to show the relationship. The value of $\mathrm{R}^{2}$ with cubic regression in three stages is highest with $\mathrm{p}<.001$. Thus, this cubic regression is used to explain the relationship between number of occupants per room and background night-time sound levels.

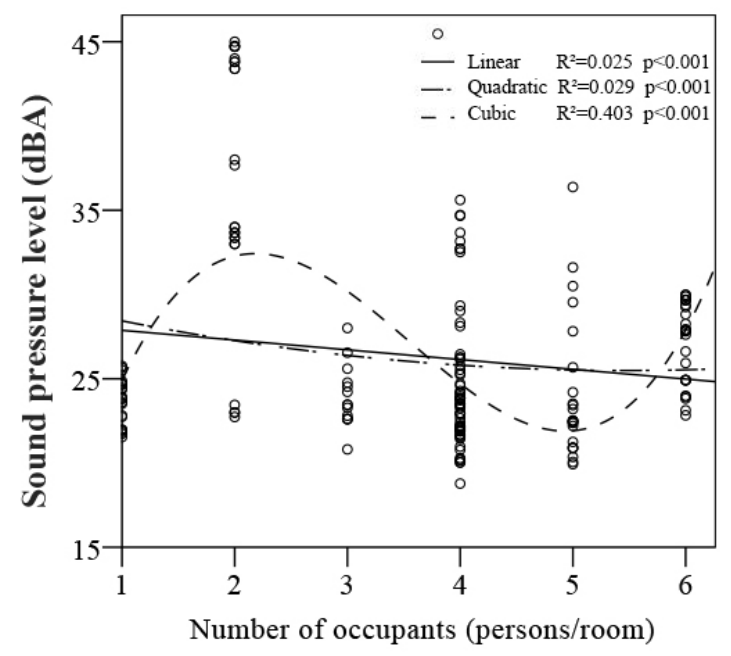

(a)

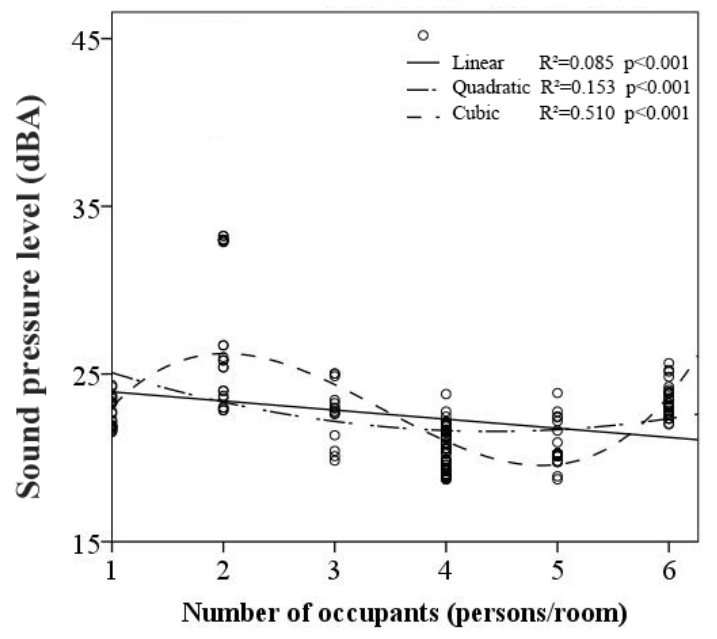

(b) 


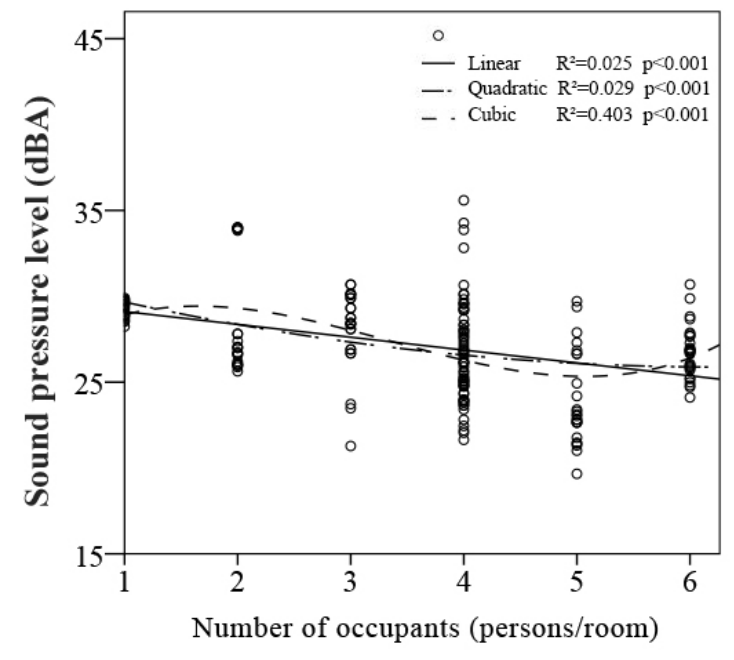

(c)

Figure 5:The effect of number of occupants on the sound level in three stages: (a) The relationship between the number of occupants and background sound level before sleep; (b) The relationship between the number of occupants and background sound level during sleep; (c) The relationship between the number of occupants and background sound level after waking up.

Figure 5 shows the relationship between number of occupants and background night-time sound levels measured with A-weight: when the number of occupants increased from one, the level of background sound pressure first increases, then decreases and finally increases again which has the same tendency with $\mathrm{R}^{2}=0.403$ ranging from 21 to $32 \mathrm{dBA}$ before sleep; 0.510 ranging from 20 to $26 \mathrm{dBA}$ during sleep; and 0.212 ranging from 25 to $30 \mathrm{dBA}$ after waking up, with significance level $p<.001$. It is interesting to note that the background sound level is highest when the number of occupants is 2 , and lowest when the number is five. The possible reasons are as follows. Firstly, students living together in dormitories form a small group $(n \geq 2)$. Group size has a certain impact on group stability and intimacy, and further changes the interaction behaviour among group members. Dyads, which consists of two people, have the strongest relationship bond and the membership is informal. Thus, the interaction is focused on both individuals, compared to one person, which increases the level of indoor noise (Simmel et al., 1950). As the group continues to grow in size, members lose intimacy and become formal. Their behaviour becomes more sensitive to the feelings of more people, reducing the active participation rate of related behaviours and activities (Bales, 1950; Darley and Latane, 1968), and therefore, reducing the noise of actions. When the number of people in a group increases to five, which is the most appropriate size for a small group, members get along more harmoniously and think more of others, which also reduces the indoor sound level. As the numbers continue to grow to six, the indoor noise level increases to a certain level again. Furthermore, compared to the other two stages, college students had the most types of activities before sleep, so the sound level varies widely. As a result, the ambient sound level before sleep is most affected by the number of people, and the sound level after waking up is least affected by the number of people.

However, some studies have suggested that fewer occupants in one bedroom, as opposed to the overcrowded dormitory environment, would have an adverse influence on students' psychological and social communication ability that cannot be ignored. The denser the dorm, the worse the residents rated their roommates (Bickman et al., 1973). A study on the improvement of hospital rooms indicated that patients treated in single rooms were more satisfied with their care than those treated in multiple-bed wards (Lawson and Phiri, 2000). Findings from Figure 5 may help to arrange the appropriate number of occupants, which indicate that when the number 3 , the room with one person is the quietest, and when the number is 4 , the room with five persons is the quietest. 


\subsection{Effect of sound level on sleep}

Table 3 provides a summary of the variables retained in the analysis for the PSQI and sleep time and relationship between sleep quality and influencing factors. Sound unrelated factors include body mass index (BMI), position of bed and day of the week, and factors related to sound include gender, grade, number of occupants, floor, and noise levels $\left(\mathrm{L}_{10}, \mathrm{~L}_{90}, \mathrm{~L}_{\mathrm{eq}}\right)$ at three stages. The results indicate that some factors, such as number of occupants, position of bed, day of the week, noise levels before sleep and noise levels during sleep were significantly correlated with sleep time, with significance level $\mathrm{p}<.01$, while there was no significant influence on the sleep time by grade, BMI, and noise levels after waking up, where significance level showed $\mathrm{p}>.10$.

Table3: Relationship between sleep quality and influencing factors.

$\begin{array}{cccccc}\text { Total } & \text { Deep sleep } & \text { Light sleep } & \text { REM } & & \\ \text { Sleep } & \text { Time } & \text { Time } & \text { Time } & \text { Number of } & \\ \text { Time } & & & & \text { Awakenings } & \text { PSQI } \\ (\min ) & (\min ) & (\text { min }) & (\min ) & \text { bouts } & \end{array}$

Sound unrelated factors

\begin{tabular}{|c|c|c|c|c|c|c|c|}
\hline \multicolumn{2}{|l|}{$\mathrm{BMI}^{\mathrm{b}}$} & 0.028 & -0.262 & 0.127 & 0.008 & 0.092 & 0.054 \\
\hline \multicolumn{2}{|c|}{ Position of bed ${ }^{b}$} & $-0.267 * *$ & $-0.242 * *$ & -0.095 & $-0.234 * *$ & 0.121 & 0.068 \\
\hline \multicolumn{2}{|c|}{ Day of the week ${ }^{\mathrm{a}}$} & $29.668^{* *}$ & $9.33 *$ & $15.321 *$ & 4.556 & 0.137 & - \\
\hline \multicolumn{8}{|c|}{ Sound related factors } \\
\hline \multicolumn{2}{|l|}{ Gender $^{\mathrm{a}}$} & 1.67 & $12.23 *$ & 7.79 & 1.71 & 0.36 & 0.02 \\
\hline \multicolumn{2}{|l|}{ Grade $^{b}$} & -0.015 & -0.038 & -0.026 & 0.035 & 0.07 & 0.086 \\
\hline \multicolumn{2}{|c|}{ Number of occupants ${ }^{b}$} & $-0.511 * *$ & $-0.450 * *$ & 0.080 & $-0.503 * *$ & $0.222 * *$ & 0.002 \\
\hline \multicolumn{2}{|l|}{ Floor $^{b}$} & 0.105 & $0.154^{*}$ & 0.007 & 0.105 & $-0.182 *$ & 0.063 \\
\hline \multirow{3}{*}{$\begin{array}{l}\text { Before } \\
\text { sleep }\end{array}$} & $\mathrm{L}_{10}{ }^{\mathrm{b}}$ & $0.278^{* *}$ & -0.062 & $0.244 * *$ & $-0.299 *$ & 0.034 & -0.093 \\
\hline & $\mathrm{L}_{90}{ }^{\mathrm{b}}$ & 0.02 & -0.006 & $0.260 * *$ & -0.136 & -0.066 & -0.05 \\
\hline & $\mathrm{L}_{\mathrm{eq}}{ }^{\mathrm{b}}$ & $0.218 * *$ & -0.059 & $0.266^{* *}$ & $-0.221^{*}$ & 0.028 & -0.111 \\
\hline \multirow{3}{*}{$\begin{array}{l}\text { During } \\
\text { sleep }\end{array}$} & $\mathrm{L}_{10}{ }^{\mathrm{b}}$ & -0.133 & -0.034 & $0.193 * *$ & -0.038 & -0.003 & -0.071 \\
\hline & $\mathrm{L}_{90}{ }^{\mathrm{b}}$ & -0.003 & $-0.382 * *$ & $0.196^{* *}$ & $-0.328 * *$ & 0.131 & $0.354 *$ \\
\hline & $\mathrm{L}_{\mathrm{eq}}{ }^{\mathrm{b}}$ & 0.025 & $-0.186^{* *}$ & $0.229^{*}$ & $-0.121 *$ & -0.04 & -0.044 \\
\hline After & $\mathrm{L}_{10}{ }^{\mathrm{b}}$ & -0.158 & -0.182 & 0.077 & 0.155 & 0.052 & 0.049 \\
\hline waking & $\mathrm{L}_{90}{ }^{\mathrm{b}}$ & 0.122 & 0.082 & 0.16 & -0.096 & 0.034 & 0.127 \\
\hline up & $\mathrm{L}_{\mathrm{eq}}{ }^{\mathrm{b}}$ & -0.091 & -0.149 & 0.099 & -0.16 & 0.03 & 0.032 \\
\hline
\end{tabular}

$* * \mathrm{p}<0.01 ; * \mathrm{p}<0.05$.

$\mathrm{L}_{10}$. Peak sound levels; $\mathrm{L}_{90}$. Background sound levels; $\mathrm{L}_{\mathrm{eq}}$. Equivalent sound levels. 
a Mean difference.

b Correlation coefficients.

It is necessary to indicate that number of occupants was found to be the most significant factor affecting sleep time, and the more occupants, the less total sleep time $(\mathrm{r}=-.511, \mathrm{p}<.01)$, deep sleep time $(r=-.450, p<.01)$, REM time $(r=-.503, p<.01)$ and the more awakenings bouts $(\mathrm{r}=-.222, \mathrm{p}<.01)$ because of its significant effect on sound levels and other behavioural influences. Besides, sleep time differed significantly by day of the week (weekdays or weekends), with significance level $\mathrm{p}<.01$. Similar results that mean bedtimes $(01: 44, \mathrm{SD}=79$ minutes $)$ were delayed and mean rise times $(10: 08, \mathrm{SD}=88$ minutes $)$ were extended on weekends was found in a survey on sleep for college students in an American Midwest college (Van Dongen et al., 2003). College students have longer total sleep time on weekends, mainly due to the course schedules in college, as they do not need to wake up to attend class and instead wake up naturally on weekends. Bed position was also significantly positively correlated with sleep duration, with significance level $\mathrm{p}<.01$. Living in the lower bunk and near the door affected sleep duration, as it was affected by more roommate activity and corridor noise, which was consistent with results of self-rated sleep quality shown in Figure 4(b).

As for the effects of sound level, previous studies have suggested that environmental noise causes increased arousal, decreased sleep duration, fragmented sleep, and decreased deep sleep and REM sleep (Clark and Stansfeld, 2007; Muzet, 2007). The relationship in Table 3 is similar to results from existing research, especially for deep sleep time and REM sleep time. $\mathrm{L}_{90}$ and $\mathrm{L}_{\mathrm{eq}}$ during sleep were negatively correlated with deep sleep time $(r=-.382$ and -.186 , respectively, $p$ $<.01)$ and $\mathrm{L}_{90}$ during sleep was also negatively correlated with deep sleep time ( $\mathrm{r}=-.328$ and -0.186 , respectively, $\mathrm{p}<.01$ ). Moreover, light sleep time was found to be significantly positively correlated with sound pressure level before and during sleep, with significance level $p<.01$. It is noticeable, however, that $\mathrm{L}_{10}$ and $\mathrm{L}_{\mathrm{eq}}$ before bedtime are positively correlated with total sleep duration $(\mathrm{r}=.278$ and .218 , respectively, $\mathrm{p}<.01)$, which is contrary to results from existing research. This occurs for multiple reasons. Sleep deprivation is one of the most common causes of daytime sleepiness among college-aged students. Disturbed by noise before sleep, they go to bed late. If they get up at the usual time, they will not get enough sleep, resulting in sleepiness. Then, some of them will abandon other plans for the morning and continue to sleep to get adequate sleep, which may cause them to sleep longer without any pressure.

Next, regression analyses were used to establish the regression curves of sleep time and noise levels. REM sleep has been identified as a time of learning and memory processing and has been considered in many related studies (Eberhardt and Akselsson, 1987; Kuroiwa et al., 2002). Deep sleep time is an important indicator of sleep quality as it usually occurs early in the sleep cycle and is less affected by total sleep time (Brunner et al., 1990; Ebb and Agnew, 1971). Therefore, we focused on REM sleep and deep sleep time. $\mathrm{L}_{90}$ during sleep were found to be significant factors ( $\mathrm{r}$ $=-.328$ and -.382 , respectively, $\mathrm{p}<.01$ ). Regression curves of REM sleep time and $\mathrm{L}_{90}$, and deep sleep and $\mathrm{L}_{90}$ were established, as shown in Figure 7. There have been few studies on the effects of noise below $30 \mathrm{~dB}$ on sleep before, which was therefore considered an appropriate range (Basner and McGuire, 2018). 


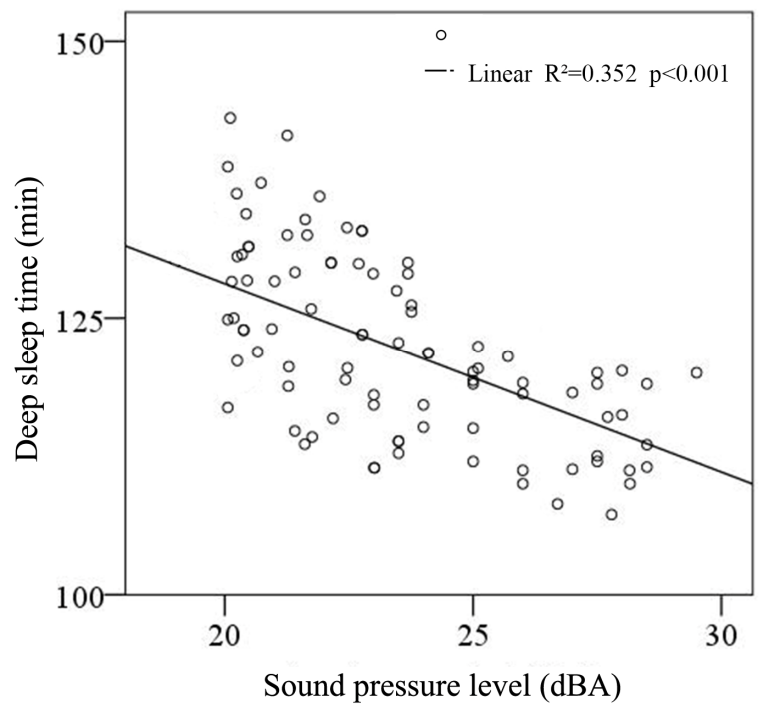

(a)

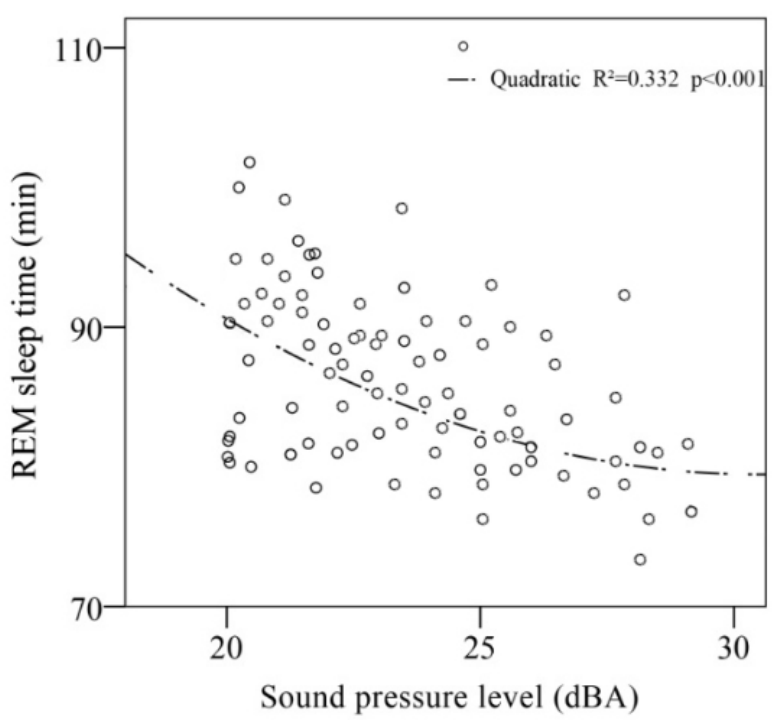

(b)

Figure 6: The relationship between background sound level and sleep time during sleep: (a) The relationship between background sound level and deep sleep time; (b) The relationship between background sound level and REM sleep time.

Figure 6(a) shows the relationship between deep sleep time and $\mathrm{L}_{90}$ during sleep: $\mathrm{R}^{2}$ was .352 , estimated coefficient parameter was -1.7 , with significance level $p<.001$. The results indicate that deep sleep time takes a linear trend of continuous decrease as the level of sound level increases. When background sound level increased from 20 to $30 \mathrm{dBA}$ in bedrooms in the residence hall, deep sleep time of college students decreased 1.7 minutes per dBA. Figure 6(b) shows the relationship between REM sleep time and $\mathrm{L}_{90}$. Different regression curves, including linear and quadratic, were used to determine the best fit to show the relationship, as measured by the value of the coefficient of determination R2 and statistically significant differences. The value of R2 with quadratic regression was .332, with significance level $\mathrm{p}<.001$ and linear regression was .223 , with significance level $p<.001$, which indicates that the quadratic regression is the best fit to illustrate the relationship that REM sleep time takes a slow downward trend as the level of sound level increases. Through the estimated coefficient parameter linear curve, REM sleep time may decrease 1.4 minutes per $\mathrm{dBA}$ as sound level increases.

The relationship between sleep disturbances assessed by the PSQI and sound level were also 
analysed. However, the correlation was not significant, unlike results in extant literature (Basner and McGuire, 2018). Sleep environment in the residence hall is complicated, with many influencing factors; hence, the influence of sound level change is not very significant on the PSQI scores.

On the basis of the above results, to improve the sound environment of sleep, the following measures can be taken. Firstly, the dorm bed mode can be adjusted to more loft beds with desks to reduce the influence of roommates' activities. Secondly, the less the number of occupants in each dorm, the more likely they were to get sufficient sleep. Additionally, sound levels need to be reduced during sleep and before sleep to create a more suitable sleeping environment.

\subsection{Effect of sound sources on sleep}

In the assessment, noise sources in the sound environment of sleep in the dormitory were classified as indoor and outdoor noise sources, and indoor noise sources comprised dormitory and other areas. In addition, in order to avoid the impact of some activities, the evaluation of dormitory activities was added to the questionnaire. Perception of and disturbance from noise sources were rated for the month in three stages: before sleep, during sleep, and after waking up.

As indicated in Table 4, the most common perceived source of noise that caused sleep disturbance was noise caused by conversations of other roommates $(77.42 \%)$, followed by noise caused by the collision of objects/furniture/door (70.97\%), footsteps in the bedroom (67.74\%). Noise caused by roommates' sleep-related activities was the most common source of activities $(67.74 \%)$.

Table 4: Perceived sources of noise by college students in the residence hall.

\begin{tabular}{|c|c|c|c|}
\hline Perceived sources of noise & $\begin{array}{c}\text { All } \\
(\mathrm{n}=90)\end{array}$ & $\begin{array}{l}\text { Number }(\%) \text { of Participants } \\
\text { undisturbed sleep } \\
(\mathrm{n}=28)\end{array}$ & $\begin{array}{l}\text { Number }(\%) \text { of Participants } \\
\text { disturbed sleep } \\
(\mathrm{n}=62)\end{array}$ \\
\hline Road traffic & $36.67 \%$ & $35.71 \%$ & $37.1 \%$ \\
\hline Construction/industry. & $33.33 \%$ & $25 \%$ & $37.1 \%$ \\
\hline Wind/rain/storm/lightning & $24.44 \%$ & $14.29 \%$ & $29.03 \%$ \\
\hline Construction equipment & $26.67 \%$ & $21.43 \%$ & $29.03 \%$ \\
\hline Roommate snore & $48.89 \%$ & $57.14 \%$ & $45.16 \%$ \\
\hline Roommate conversation & $71.11 \%$ & $57.14 \%$ & $77.42 \%$ \\
\hline Roommate whispery & $57.78 \%$ & $57.14 \%$ & $58.06 \%$ \\
\hline Footsteps in the bedroom & $64.44 \%$ & $57.14 \%$ & $67.74 \%$ \\
\hline Keyboard/mouse click & $52.22 \%$ & $53.57 \%$ & $51.61 \%$ \\
\hline $\begin{array}{c}\text { Collision of } \\
\text { objects/furniture/door }\end{array}$ & $66.67 \%$ & $57.14 \%$ & $70.97 \%$ \\
\hline Footsteps in the corridor & $55.56 \%$ & $50 \%$ & $58.06 \%$ \\
\hline Conversation in the corridor & $53.33 \%$ & $46.43 \%$ & $56.45 \%$ \\
\hline Activities in the next room & $37.78 \%$ & $42.86 \%$ & $35.48 \%$ \\
\hline
\end{tabular}


Roommate sleep-related activity

Roommate study, entertainment activities

Figure 7 shows the perception of noise and disturbance of noise from various sound sources in three stages. In order to analyse the significance of disturbance from different noise sources, Pearson's correlation analysis was used to calculate the relationship among disturbance of noise sources and sleep time simultaneously.

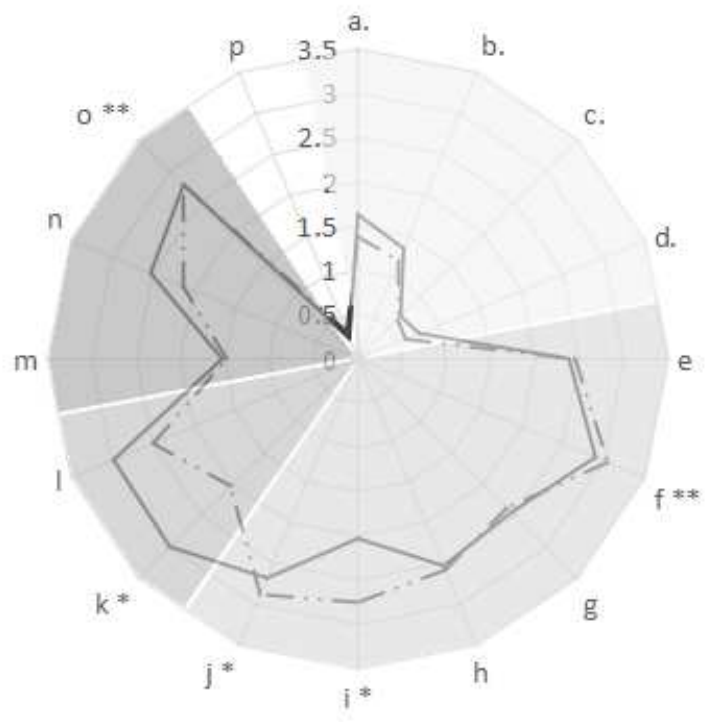

(a)

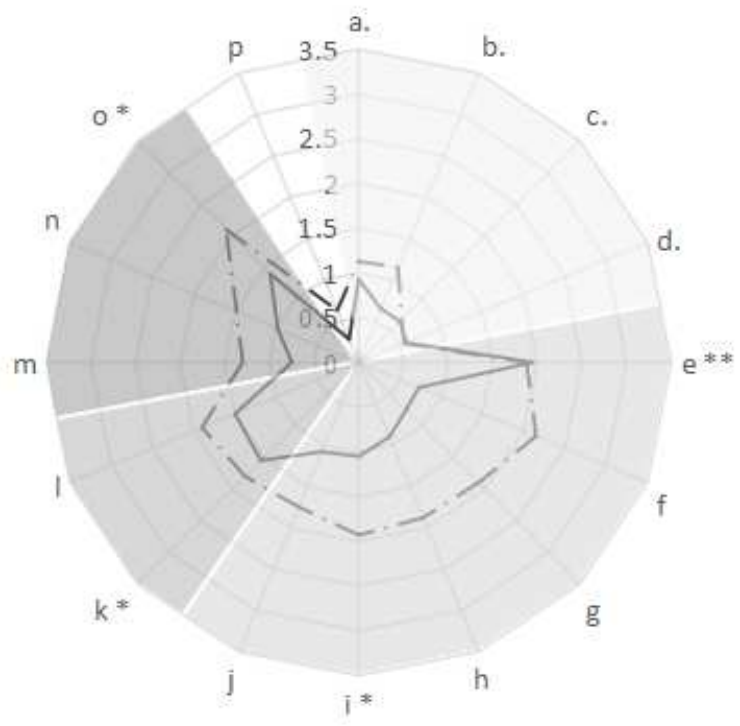

(b) 


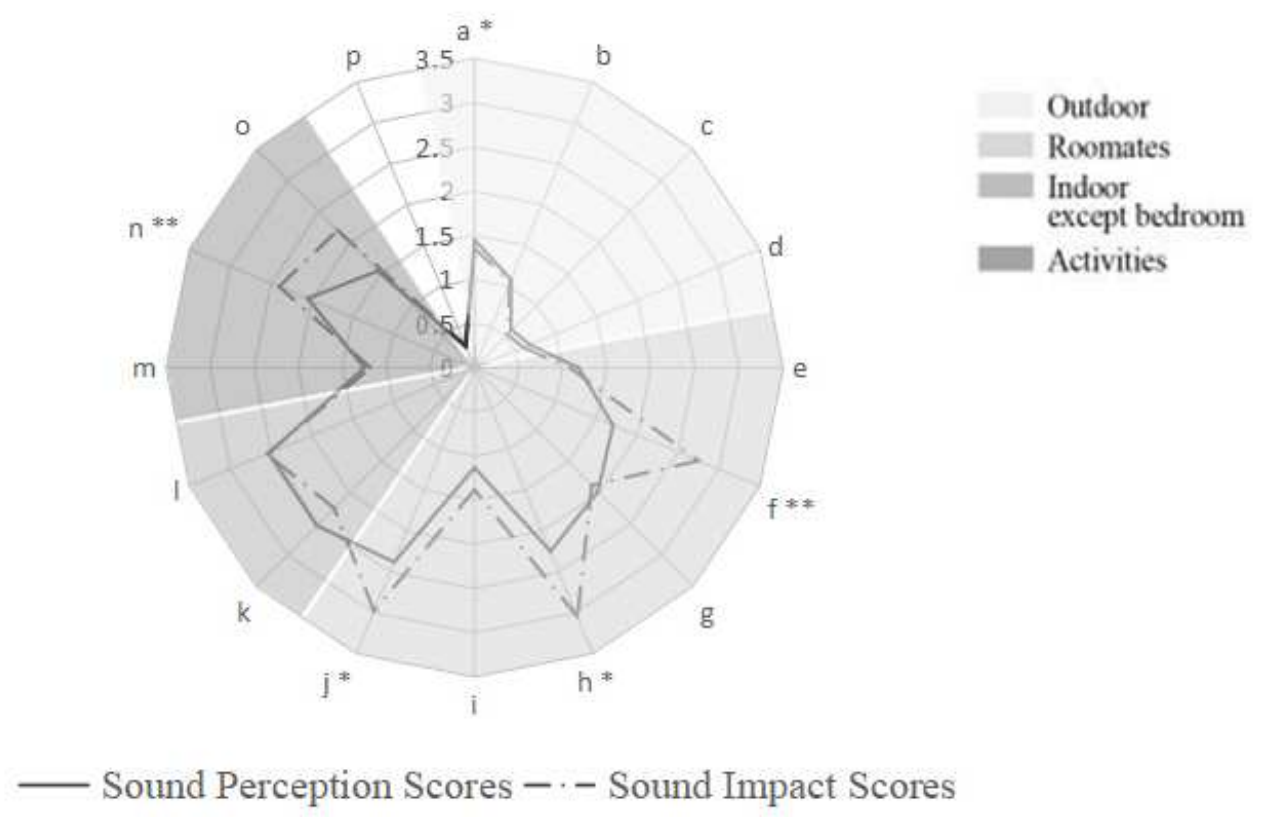

(c)

Figure 7: Evaluation of noise sources in different sleep stages: (a) Evaluation of noise sources before sleep; (b) Evaluation of noise sources during sleep; (c) Evaluation of noise sources after waking up.

$* * \mathrm{p}<0.01 ; * \mathrm{p}<0.05$.

a. Road traffic. b. Construction/industry. c. Wind/rain/storm/lightning. d. Construction equipment.

e. Roommates snore. f. Roommates conversation. g. Roommates whispery. h. Footsteps in the bedroom. i. Keyboard/mouse click. j. Collision of objects/furniture/door. k. Footsteps in the corridor. 1. Conversation in the corridor. m. Activities in the next room. n. Roommate sleep-related activity. o. Roommate study, entertainment activities. p. Others.

Before sleep, noise from roommates' conversation, and study and entertainment activities have a significant effect on sleep duration $(r=.315$ and .322 respectively, $\mathrm{p}<.01)$. As Figure7(a) shows, both perception and disturbance evaluation scores of outdoor noise are far less than indoor noise, especially the scores of wind/rain/storm/lightning and construction equipment, which range between 0.5 to 1 , which means that participants can hardly hear these two kinds of noises and have not been influenced by them. Besides, most of indoor noises were perceived at roughly the same range, with the scores from 2 to 3 . In addition, two types of noise are noteworthy. The effect of keyboard sound on the participants was much greater than the perception of the sound, with a difference in scores of nearly one. The effect of corridor footsteps on participants was much less than perceived. The results showed that participants were more sensitive to keyboard sounds and less sensitive to corridor footsteps in the acoustic environment before sleep.

During sleep, noise from roommates' snores have a significant effect on sleep duration ( $\mathrm{r}$ $=.35, \mathrm{p}<.01)$. Participants were more sensitive to noise, and the effect scores for almost all types of noise were greater than the perceived evaluation scores. In particular, the rating of bedroom noises including roommates' conversation, roommates' whispers, footsteps in the bedroom, and keyboard/mouse click varied even more, which means participants are much more sensitive to them. In the meantime, the participants' evaluation of indoor noise was generally similar, with a score of two. In addition, roommates' study and entertainment activities became the major behavioural influence, because sleep activities reduced in this stage.

After waking up, noise from roommates' conversation and roommates' sleep-related activity had a significant effect on sleep duration $(r=.333$ and .281 , respectively, $\mathrm{p}<.01)$. Participants rated the perception and influence of other sounds equally, except for roommate conversation, roommate whispers, footsteps in the bedroom, and footsteps in the corridor. It is worth noting that 
in the indoor noise, the perception and impact of keyboard/mouse click sound are the least significant, with significance level $p>.05$. Participants were more sensitive to roommate activities, especially those related to getting up, such as roommates' conversation, roommates' whispers, footsteps in the bedroom.

The above results are analysed and interpreted as follows. In the pre-sleep stage, there are fewer road vehicles at night and less construction work, hence the noise level is lower. The main activities of the participants in this stage are preparing for sleep (or falling asleep) and staying up late to study and play. Sometimes there is snoring when someone is asleep, which is not common. At this time, the biggest impact is the study and entertainment activities of the roommates. Some roommates always talk to each other and some engage in computer-related activities. It can be seen that the noise generated by these activities has the biggest impact as shown in Figure 7(a). In addition, due to the poor sound insulation of the door, the corridor noise perceived by the participants is obvious, but the influence was relatively small, because these footsteps and conversations are not persistent. In the sleep stage, with roommates falling asleep, snoring became the main noise, and often lasted for a long time. In the stage after waking up, while most of the students choose to wake up earlier to study in the classroom, there were still some students learning in the bedroom. Other people were either sleeping or performing activities related to getting up, getting enough sleep. The participants who were sensitive to several kinds of sounds were easily woken up. In general, noise perception before sleep is the most significant, followed by noise heard after waking up, and the sounds perceived during sleep are slightly lower, which is the same as the effect analysis. Therefore, arranging uniform schedules and establishing clear regulations on student sleeping behaviours are needed to avoid the interference of others' sleeping.

Roommates should reduce some noises including conversation, keyboard/mouse clicks, and collision of objects/furniture/doors. Furthermore, study rooms can be set aside for some students' evening study and entertainment activities in the residence hall, so as not to affect other students' sleep.

\section{Conclusion}

Based on the objective measurements and subjective questionnaire survey of sleep quality and sound environment, this study examined the different influences of factors in the sound environment on sleep quality. Based on our findings, several conclusions can be drawn.

First, sound environment was the third biggest factor but the most influential environmental factor among 15 disruptors in PSQI affecting sleep in college students, of which about $50 \%$ of participants had trouble sleeping. Second, the number of occupants per room was a significant factor affecting background sound level of sleep, which was the highest when the number of occupants was two, and the lowest when the number was five. Other influential factors included gender and floor. Third, sound level is one of the significant influential factors on sleep quality. Total sleep time of college students living in Chinese residence halls was negatively correlated with the peak sound levels, with significance level $\mathrm{p}<.01$, while deep sleep time and REM sleep time decreased 1.7 minutes and 1.4 minutes per dBA as background sound level increased, with significance level $p<.001$. In addition, each type of noise had different effects at each stage. The sound environment before sleep is the most complicated and influential, while students were the most sensitive to the noise during sleep. The most common perceived sources of noise disturbing sleep were their roommate conversations $(77.42 \%)$, followed by collision of objects/furniture/door $(67.74 \%)$, and footsteps in the bedroom $(67.74 \%)$.

The present study can help to enhance the sleep quality of Chinese college students through improvements in the sound environment. Firstly, the number of occupants must be adjusted to create a quiet sleeping environment, specifically when the number is three or less than three the room with one person is better, and when the number is four or more than four, rooms with five persons is better. Next, the dorm bed mode can be adjusted to have more loft beds with desks to reduce the influence of roommates' activities. Last, arranging uniform schedules and setting up enough study rooms for some students' evening activities in residence hall are needed to avoid the interference to others' sleep. 
The limitations and questions to be further discussed of this study are as follows. First, sleep quality data of whole night were collected by actigraphy. But more detailed sleep data in the specific stages of sleep could not be provided and subtle physiological changes could not be detected. In future studies, polysomnography and other physiological measurements will be used for thorough research. Second, because of the limited functions of noise dosimeters, only the indoor sound level was used in this study as has been done in most studies so far. It has been proposed that noise exposure characteristics play also an import role and that number of events or the peak level of noise events should be analysed which were not available in this study (Basner et al., 2011). In the following study, more detailed noise characteristics such as duration and clarity will be considered and noise events will be recorded, which might provide some insight on the mechanism of noise influenced sleep for college students.

\section{Acknowledgements}

This study was supported by the National Natural Science Foundation of China (51678180, 51308145, and 51608147).

\section{References}

Amlander, C.J., Fuller, P.M. Basics of Sleep Guide. 2nd ed. Westchester, IL: Sleep Research Society. (2005)

Ancoli-Israel, S., Cole, R., Alessi, C. M. Chambers, W. Moorcroft, C.P. Pollak, The role of actigraphy in the study of sleep and circadian rhythms, Sleep. 26 (2003), pp. 342-92.

Astin, A.W., Astin, H.S. Sleep deprivation and the development of leadership and need for cognition during the college years, Journal of Adolescence 73 (2019), pp. 95-99.

Azadboni, Z.D., Talarposhti, R.J., Ghaljahi, M., Mehri, A., Aarabi, S., Poursadeghiyan, M., Abbasi, M. Effect of Occupational Noise Exposure on Sleep among Workers of Textile Industry, Jounrnal of clinical and diagnostic research. 12 (3) (2018), pp. 18-21.

Bakker, R.H., Pedersen, E., van den Berg, G.P., Stewart, R.E., Lok, W., Bouma, J. Impact of wind turbine sound on annoyance, self-reported sleep disturbance and psychological distress, Science of the Total Environment. 425 (2012), pp. 42-51.

Bales, R.F. "A Set of Categories for the Analysis of Small Group Interaction" in American Sociological Review. 15 (2) (1950), pp. 257-263.

Basner, M., McGuire, S. WHO Environmental Noise Guidelines for the European Region: A Systematic Review on Environmental Noise and Effects on Sleep, International Journal of Environmental Research and Public Health. 15 (3) (2018)

Basner, M., Müller, U., Griefahn, B. Practical guidance for risk assessment of traffic noise effects on sleep, Appl Acoust. (2010)

Basner, M., Muller, U., Elmenhorst, E.M. Single and combined effects of air, road, and rail traffic noise on sleep and recuperation, Sleep. 34 (1) (2011), pp. 11-23.

Bickman, L., Teger, A., Gabrieler, T. Dormitory density and helping behavior, Environment and behavior. 5 (1973), pp. 465-490.

Brunner, D.P., Dijk, D.J., Tobler, I. Effect of partial sleep deprivation on sleep stages and EEG power spectra: Evidence for non-REM and REM sleep homeostasis, Electroencephalography and Clinical Neurophysiology. 75 (6) (1990), pp. 492-499.

Buysse, D.J., Reynolds, C.F., Monk, T.H. The Pittsburgh SleepQuality Index: a new instrument for psychiatric practice and research.Psychiatry Res. 28 (1989), pp. 193-213.

Carpenter, J.S., Andrykowski, M.A. Psychometric evaluation of the Pittsburgh Sleep Quality Index, J Psychosom Res. 45 (1998), pp. 5-13.

Chen, L.D., Liu, C.Y., Ye, Z.N., Wang, B.D., He, S.B. Assessment of sleep quality using cardiopulmonary coupling analysis in patients with Parkinson's disease, Brain and behavior. 8 (5) (2018)

Clark, C., Stansfeld, S. The Effect of Transportation Noise on Health and Cognitive Development: A Review of Recent Evidence, International Journal of Comparative Psychology. (2007)

Clegg-Kraynok, M.M., McBean, A.L., Montgomery-Downs, H.E. Sleep quality and characteristics 
of college students who use prescription psychostimulants nonmedically, Sleep Med. 12 (6) (2011), pp. 598-602.

Cysarz, D., Linhard, M., Seifert, G., Edelhauser, F. Sleep instabilities assessed by cardiopulmonary couplinganalysis increase during childhood and adolescence, Frontiers in physiology. 9 (2018)

Darley, J.M., Latane, B. Bystander intervention in emergencies: Diffusion of responsibility, Journal of Personality and Social Psychology. 8 (1968), pp. 377-383.

Eberhardt, J.L., Strale, L.O., Berlin, M.H. The influence of continuous and intermittent traffic noise on sleep, J Sound Vib. 116 (3) (1987), pp. 445-64.

Ebb, W.B., Agnew, H.W. Stage 4 sleep: Influence of time course variables, Science. 174 (2016), pp. 1354-1356.

Eberhardt, J.L., Akselsson, K.R. The disturbance by road traffic noise of the sleep of young male adults as recorded in the home, J Sound Vib. 114 (3) (1987), pp. 417-34.

Evandt, J., Oftedal, B., Krog, N.H., Nafstad, P., Schwarze, P., Aasvang, G.M. A population-based study on nighttime road traffic noise and insomnia, Sleep. 40 (2017)

Feeney, B.C. A Simple Guide to IBM SPSS Statistics for Version 20.0, Cengage Learning: Boston, MA, USA. (2012)

Hershner, S.D., Chervin, R.D. Causes and consequences of sleepiness among college students, Nature \&Science of Sleep. (2014), pp. 673-84.

Ising, H., Ising, M. Chronic Cortisol Increases in the First Half of the Night Caused by Road Traffic Noise, Noise Health. 4 (2002), pp. 13-21.

Gawlik, K., Melnyk, B.M., Tan, A., Amaya, M. Heart checks in college-aged students link poor sleep to cardiovascular risk, Journal of american college health. 67(2) (2019), pp. 113-122.

George, C.F. Sleep apnea, alertness, and motor vehicle crashes, Am J Respir Crit Care Med. (2007) Gilbert, S.P., Weaver, C.C. Sleep quality and academic performance in university students: a wake-up call for college psychologists, J. Coll. Stud. Psychother. 24 (4) (2010), pp. 295-306.

Gilbert, S.S., van den Heuvel, C.J., Ferguson, S.A., Dawson, D. Thermoregulation as a sleep signalling system, Sleep Med Rev. 8 (2004), pp. 81-93.

Gregory, J.M., Xie, X., Mengel, S.A. SLEEP (sleep loss effects on everyday performance) model, Aviat Space Environ Med. (2004)

Harbin Institute of Technology, Basic statistics of Harbin Institute of Technology. Available online: http://www.hit.edu.cn/340/list.htm

Kang, S., Ou, D., Mak, C. The impact of indoor environmental quality on work productivity in university open-plan research offices, Building and Environment. (2017)

Kuroiwa, M., Xin, P., Suzuki, S., Sasazawa, Y., Kawada, T. Habituation of sleep to road traffic noise observed not by polygraphy but by perception, J Sound Vib. 250 (1) (2002)

Kwak, K.M., Ju, Y.S., Kwon, Y.J., Chung, Y.K., Kim, B.K., Kim, H., Youn, K. The effect of aircraft noise on sleep disturbance among the residents near a civilian airport: a cross-sectional study, Annals of Occupational and Environmental Medicine. (2016)

Lan, L., Lian, Z.W., Huang, H.Y., Lin, Y.B. Experimental study on thermal comfort of sleeping people at different air temperatures, Build. Environ. 73 (2014), pp. 24-31.

Lawson, M. Phiri, Hospital design. Room for improvement, The Health Service Journal. 110 (2000), pp. 24-26.

Lee, P.J., Shim, M.H., Jeon, J.Y. Effects of different noise combinations on sleep, as assessed by a general questionnaire, Appl. Acoust. 71 (9) (2010), pp. 870-875.

Lercher, P., Brink, M., Rudisser, J., Van Renterghem, T., Botteldooren, D., Baulac, M., Defrance, J. The effects of railway noise on sleep medication intake: Results from the ALPNAP-study, Noise Health. 12 (2010), pp. 110-119.

Lund, H.G., Reider, B.D., Whiting, A.B., Prichard. J.R. Sleep patterns and predictors of disturbed sleep in a large population of college students, J Adolesc Health. 46 (2) (2010), pp. 124-132.

Maffei, L., Iannace, G., Masullo, M., Nataletti, P. Noise exposure in school gymnasia and swimming pools, Noise Control Engineering Journal. 57 (2009), pp. 603-612.

Martin , J.L., Hakim, A.D. Wrist actigraphy, Chest. 139 (2011), pp. 1514-27. 
Michaud, D.S., Feder, K., Keith, S.E., Voicescu, S.A., Marro, L., Than, J., Guay, M., Denning, A., Murray, B.J., Weiss, S.K., Villeneuve, P.J., van den Berg, F. Bower, T. Effects of wind turbine noise on self-reported and objectivemeasures of sleep, Sleep. 39 (1) (2016),pp. 97-109.

Ministry of Education of the People's Republic of China, Statistical Bulletin of National Education Development in 2018. Available online: https://www.moe.gov.cn/jyb_sjzl/sjzl_fztjgb/201907/t20190724_392041.html.(accessed on 24 July 2019).

Muzet, A. Environmental noise, sleep and health, Sleep medicine reviews. 11 (2) (2007), pp. 135-142.

Öhrström, E., Skanberg, A. Sleep disturbances from road traffic and ventilation noise: laboratory and field experiments, J Sound Vib. 271 (2004), pp. 279-96.

Orzeł-Gryglewska, J. Consequences of sleep deprivation, Int J Occ Med Environ Health. (2010)

Park, M.J., Yoo Jee, H., Cho, B.W. Noise in hospital rooms and sleep disturbance in hospitalized medical patients, Environmental health and toxicology. 29 (2014)

HuffcuttJ.J. Pilcher, A.I. Huffcutt, Effects of sleep deprivation on performance: a meta-analysis, Sleep. (1996)

Pirrera, S., Valck, E. D., Cluydts, R. Field study on the impact of nocturnal road traffic noise on sleep: The importance of in- and outdoor noise assessment, the bedroom location and nighttime noise disturbances. Science of The Total Environment, Volumes 500-501, 1 December (2014), pp. 84-90.

Ricciardi, P., Buratti, C. Environmental quality of university classrooms: Subjective and objective evaluation of the thermal, acoustic, and lighting comfort conditions, Building and Environment. 127 (2018), pp. 23-36.

Sadeh, A. The role and validity of actigraphy in sleep medicine: anupdate, Sleep Med Rev. 15 (2011), pp. 259-67.

Schramm, P.J., Thomas, R., Feige, B., Spiegelhalder, K., Riemann. D. Quantitative measurement of sleep quality using cardiopulmonary coupling analysis: a retrospective comparison of individuals with and without primary insomnia, Sleep and breathing. 12 (2) (2013), pp. 713-721.

Simmel, G., Kurt H, W. The Sociology of Georg Simmel. Glencoe, Ill.: Free Press. (1950), pp. 118-174.

Smith, M.G., Croy, I., Hammer, O., Persson Waye, K. Vibration from freight trains fragments sleep: A polysomnography study, Science Reports. (2016)

Spira, A.P., Beaudreau, S.A., Stone, K.L. Reliability and validity of the Pittsburgh Sleep Quality Index and the Epworth Sleepiness Scale in older men, J Gerontol A Biol Sci Med Sci. 67 (2012)

Stansfeld, S., Haines, M., Brown, B. Noise and health in the urban environment, Rev Environ Health. 15 (2000), pp. 43-82.

Strauch, C., Brandt, S., Edwards-Beckett, J. Implementation of a quiet hour: effect on noise levels and infant sleep states. 12 (2) (1993)

Sexton-Radek, A. Hartley, College Residential sleep environmental, Psychological Reports: Mental \& Physical Health. 113 (3) (2013), pp. 903-907.

Thomas, R.J., Mietus, J.E., Peng, C.K., Goldberger, A.L. An ECG-based technique to assess cardiopulmonary coupling during sleep, Sleep. 28 (2005), pp. 1151-1161.

Thomas, K.P., Salas, R.E., Gamaldo, C., Chik, Y., Huffman, L., Rasquinha, R., Hoesch, R.E. Sleep rounds: A multidisciplinary approach to optimize sleep quality and satisfaction in hospitalized patients, J. Hosp. Med. 7 (2012), pp. 508-512.

Thomée, S., Eklöf, M., Gustafsson, E., Nilsson, R., Hagberg, M. Prevalence of perceived stress, symptoms of depression and sleep disturbances in relation to information and communication technology (ICT) use among young adults - an explorative prospective study, Comput Human Behav.23 (3) (2007), pp. 1300-1321.

Van Dongen, H.P., Maislin, G., Mullington, J.M., Dinges, D.F. The cumulative cost of additional wakefulness: dose-response effects on neurobehavioral functions and sleep physiology from chronic sleep restriction and total sleep deprivation, Sleep. 26 (2) (2003), pp. 117-126. 
Walsh, J.K., Muehlbach, M.J., Humm, T.M., Dickins, Q.S., Sugerman, J.L., Schweitzer, P.K. Effect of caffeine on physiological sleep tendency and ability to sustain wakefulness at night, Psychopharmacology. 101 (2) (1990), pp. 271-273.

Weyde, K.V., Krog, N.H., Oftedal, B., Evandt, J., Magnus, P., Øverland, S. Nocturnal road traffic noise exposure and children's sleep duration and sleep problems, Int J Environ Res Public Health. 14 (5) (2017), pp. 491.

Zaharna, M., Guilleminault, C. Sleep, noise and health: review, Noise Health. (2010) 